\title{
Rheumatology and COVID-19 at 1 year: facing the unknowns
}

\author{
Leonard Calabrese (10 , ${ }^{1}$ Kevin L Winthrop (1) ${ }^{2}$
}

This issue of the Annals of the Rheumatic Diseases includes the freshly minted European Alliance of Associations for Rheumatology (EULAR) points to consider on the pathophysiology and use of immunomodulatory therapies in COVID-19. ${ }^{1}$ This publication adds to the formidable extant literature on COVID-19, which is of particular interest to rheumatology as the field has become an important stakeholder in the investigation of immune-based therapies targeting the inflammatory phase of SARS-CoV-2 infection. From the outset, we believe these authors recognised that their mission to provide real-time analysis in a timely and reflective manner was a Sisyphean task, as at the time of this writing, over 113635 publications have been posted on PubMed and MedRxiv alone, largely in the past 12 months (search date 14 February 2021). To their credit, the systematic review process in the accompanying literature search ${ }^{2}$ even included a 'hand search' of the ever increasingly quoted 'grey literature' consisting of the torrent of press releases on new drugs and therapies. These types of sources in the COVID-19 field are of particular importance as they are often amplified by social media, creating what some may refer to as 'epistemic chaos', and posing an increasing threat to the iterative method of science (eg, the early embrace of hydroxychloroquine). Thus, these points to consider should be viewed as ephemeral and will need ongoing curation to maximise their value in the months ahead.

To poise ourselves to best meet this challenge, we thought it logical to not focus on what has already happened but rather to attempt to selectively gaze ahead and consider some key areas of interest to the field of rheumatology which will likely impact our profession and our patients.

\footnotetext{
${ }^{1}$ Rheumatology/lmmunology, Cleveland Clinic, Cleveland, Ohio, USA

${ }^{2}$ School of Public Health, Oregon Health \& Science University, Portland, Oregon, USA
}

Correspondence to Dr Leonard Calabrese, Rheumatology/lmmunology, Cleveland Clinic, Cleveland, OH 44195, USA; calabrl@ccf.org

\section{UNKNOWN NUMBER 1: COVID-19 VACCINES AND RHEUMATOLOGY}

We now have strong efficacy data reported for three different vaccine constructs: 90\%-95\% for mRNA vaccines from Pfizer $^{3}$ and Moderna, ${ }^{4} 89 \%$ for a proteinconjugate vaccine from Novovax ${ }^{5}$ and somewhat lesser efficacy for the adenoviral vaccines that have recently reported. Interestingly, the adenoviral-based AstraZeneca vaccine reported $62 \%$ efficacy in Brazil, but markedly higher efficacy in England (90\%), where mistakenly a half-dose was used as the primary vaccination followed by the correct full dose. ${ }^{5}$ The adenoviral-based Janssen vaccine reported $72 \%$ efficacy in a one-dose trial; data from their phase III trial using two doses are still pending. ${ }^{5}$ We know that these vaccines provide neutralising antibody titres and measures of cell-mediated immunity equal to or greater than that found in convalescent plasma of those with prior wild-type infection. ${ }^{6}$ We hope this implies more robust protection and for longer time periods than does natural infection, and there are data to support longer-term durability of vaccine-induced immune responses. ${ }^{6}$ Interestingly, while second cases among individuals have been reported (and in some cases had worse outcomes), the incidence of second cases in the 6-9 months after infection appears to be small, with as few as $<1 \%$ being reinfected as documented in a large public health study in England.

So what does this mean for those with immune-mediated inflammatory diseases? Most of our understanding of vaccine responses in rheumatic disease and the influence of disease-modifying antirheumatic drugs (DMARDs) on those responses has been generated by a small number of studies involving influenza, pneumococcal and tetanus vaccines, and less commonly others. In general, rituximab is well known to severely reduce the humoral response to vaccination. Both methotrexate and JAK inhibitors have been shown to decrease response to influenza or pneumococcal polysaccharide vaccinations. Tumour necrosis factor blockers and interleukin (IL)-17 blockers have been shown to have little or no effect on these vaccines. ${ }^{8}$ Very little data exist for abatacept, but likely responses are diminished. ${ }^{8}$ From an efficacy standpoint, it is likely that some of these DMARDs will diminish COVID-19 vaccine immunogenicity, raising the need to study these practical questions as soon as possible. From a safety standpoint, phase III trials have not raised any serious safety concerns, and the postmarketing period is remarkably devoid of serious adverse events despite widespread scrutiny and millions of individuals having been vaccinated. The safety of these vaccines remains to be seen in rheumatology patients, however. No vaccines currently available (or expected to be available in the near future) are live replicating vaccines, including the adenoviral vaccines, and therefore are not contraindicated in immunosuppressed patients. The potential for COVID-19 vaccines to induce disease flare or potentially new autoimmune and/or autoinflammatory complications remains unquantified. This is of particular relevance as the impact of downstream effects of innate interferon responses generated particularly by the mRNA vaccines remains unknown. Thus, efforts such as the EULAR COVAX database (https:// www.eular.org/eular_covid19_database. cfm) where rheumatology providers can report untoward effects from COVID-19 vaccines are vitally important.

The wildcards of vaccine acceptance and the evolution of new virus variants make the future impossible to predict, but our strategy at present is easy to articulate: we should vaccinate as many willing people as quickly as possible no matter the vaccine type. The rise of new variants that are less susceptible to vaccine-induced (and natural) immunity has been demonstrated already in the context of phase III trials for at least two vaccines in development, reminding us that this is likely not a 'one and done' situation. ${ }^{5}$ This virus has become endemic and commitment to long-term development and maintenance of effective vaccines will remain important for governments and industry alike. As a rheumatology community, we will need to continue to invest in the research that will guide our ability to best protect our patients.

\section{UNKNOWN NUMBER 2:}

\section{AUTOIMIMUNITY AND COVID-19}

The intersection of COVID-19 and autoimmunity is complex and bidirectional. ${ }^{3}$ For patients with pre-existing clinical or subclinical autoimmune/autoinflammatory diseases, there is potential for their 
Pre-existing immune mediated disease patients

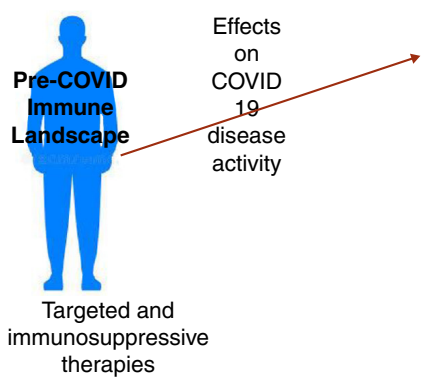

Newly acquired autoantibodies and or immune i.e.

MIS-C, MIS-A $\begin{gathered}\text { Effects of } \\ \text { infection on } \\ \text { pre-existing }\end{gathered}$
$\begin{gathered}\text { Guillain-Barre } \\ \text { others } \\ \text { disease state } \\ \text { or new onset } \\ \text { disease }\end{gathered}$
$\begin{gathered}\text { Autoimmune flares in } \\ \text { people with preexisting } \\ \text { autoimmunity }\end{gathered}$ Long COVID-19 mediated diseases

Figure 1 Bidirectional effects of COVID-19 on autoimmune/autoinflammatory diseases. MIS-A, multisystem inflammatory syndrome in adults; MIS-C, multisystem inflammatory syndrome in children. disease and/or therapies to have an effect on the clinical course of COVID-19 infection, as well as the potential for their disease to be influenced by the infection after recovery (figure 1). For those without apparent autoimmune/autoinflammatory diseases, there is the potential for new-onset immune-mediated diseases which have been anecdotally reported ${ }^{9}$ and await more critical appraisal. In terms of laboratory evidence of autoimmunity, it should not be surprising that numerous groups have documented the presence of autoantibodies including antinuclear antibodies ${ }^{10} 11$ and antiphospholipid antibodies $^{12}$ in patients with COVID-19 as mechanistically viral infections have long been known to disturb immunological tolerance. ${ }^{3}$ The biological importance of these observations remains unclear, but recently, a series of intriguing studies have suggested that these autoantibodies not only may be associated with clinical disease but also may be functioning as drivers of immunopathogenesis. The work of Knight and colleagues ${ }^{12}$ has demonstrated that not only are antiphospholipid antibodies detectable in the majority of patients with severe COVD-19 but also these antibodies were highly capable of driving thrombosis in a preclinical model used to study immunothrombosis. Mechanistically, the work of Sanz and colleagues ${ }^{10}$ not only documented the presence of autoantibodies in patients with severe COVID-19 but also described that such patients displayed hallmarks of extrafollicular B-cell activation previously described in SLE. ${ }^{13}$ In early 2021, a series of investigations have autoantibodies in hospitalised patients with COVID-19 14 and in a multicentre effort led by Utz and colleagues ${ }^{15}$ have now further documented new-onset $\operatorname{IgG}$ demonstrated reactivity to antigens associated with rare autoimmune diseases and even more frequently against cytokines correlating with immune response to SARS-CoV-2. Finally, an intriguing study by Combes and colleagues ${ }^{16}$ has demonstrated that patients with severe COVID-19 produce antibodies which functionally inhibit interferon-stimulated gene expression via an Fc-mediated mechanism. Collectively, there is a growing case that autoreactivity is more than an epiphenomenon of the autoantigenome ${ }^{17}$ potentially leading to alternative immunotherapeutic approaches that include apheresis and other strategies. Further work is urgently needed.

\section{UNKNOWN NUMBER 3: LONG COVID-19 AND RHEUMATOLOGY}

The most expansive unknown is how the yet-undefined population with symptoms persisting after recovery from both severe and mild COVID-19, a disorder now being referred to as long COVID-19 or longhaul COVID-19, will impact the field of rheumatology. ${ }^{18}$ The fact that global cases of COVID-19 now exceed 100 million and that estimates of persistent symptoms, often dominated by fatigue, musculoskeletal pain, brain fog, dyspnoea and other complaints, may be seen in one in four or more patients greater than 2 months post-'recovery'19 portends for a public health problem of massive proportions. How such patients will be managed and what the role of rheumatology will play in research and management of such patients are yet undefined. ${ }^{2021}$ For now perhaps, the most immediate challenge is to define the aetiopathogenesis of such symptoms which hopefully will inform potential therapies. Rheumatologists may have a larger role in managing such patients if inflammatory and or autoimmune mechanisms are found culpable, but this mechanism is but one which we propose is possible (box 1). For now, the immediate challenges must start with careful epidemiological and classification exercises, then move to defining potential mechanisms, before finally determining where our specialty will be placed in management of such patients. It is likely that clinical trials for such patients will include at some point immune-based therapies as they have in acute COVID-19 and where rheumatologists have played important roles. Already, most long-COVID-19 clinics are multidisciplinary and rheumatologists are contributing.

\section{UNKNOWN NUMBER 4: IMMUNOMUDULATORS IN THE TREATMENT OF COVID-19}

Over the past year, over 2600 trials have been listed on the Global Coronavirus COVID-19 Clinical Trial Tracker (https:// www.covid-trials.org/), including over 100 involving IL-6 and JAK inhibitors alone (search date 21 February 2021). This is an extraordinarily fast-moving area and, to date, with the exception of glucocorticoids, ${ }^{22}$ no drugs have had a dramatic impact on mortality. The case of IL-6 inhibitors has been particularly vexing as numerous randomised and nonrandomised prospective trials have yielded highly mixed results ${ }^{23}$ until recently. In February, the Randomised Evaluation of COVID-19 Therapy trial demonstrated that tocilizumab reduces the risk of death

\section{Box 1 Possible aetiopathogeneic mechanisms of long COVID-19:}

1. End organ damage as sequelae of severe COVID-19.

2. Effects of persistent and possible occult viral infection.

3. Exacerbation of underlying comorbidities, including clinically occult autoimmune and autoinflammatory disease states.

4. De novo autoimmune or autoinflammatory disease from persistent immune activation or autoimmunity.

5. Unknown mechanisms

- Can be based on more than one mechanism in a given patient. 
(absolute risk reduction $4 \%$ at 28 days) when given to hospitalised patients with severe COVID-19. This has been the largest trial of IL- 6 inhibition to date and gives us pause in our effort to critically appraise where IL-6 inhibition will now fit in the treatment of severe COVID19. ${ }^{25}$ Reasons for the somewhat surprising data may include the power of its sheer size (ie, over 2000 patients on active IL-6 inhibition), the fact that $82 \%$ also received glucocorticoids (now a standard of care for serious disease) and improvements in general care of patients with serious disease. Moving ahead, we now await results of numerous other agents targeting multiple pathways both singly and combination protocols. Perhaps instead of finding a dramatic drug, we will ultimately whittle away at COVID-19 morbidity and mortality by iterative steps.

As the Nobel Laureate Niels Bohr once said 'Prediction is very difficult, especially if it's about the future!' but in COVID-19 that is exactly what we must do. These are but a few of the many pressing issues for the field of rheumatology to consider. We know there will be many more, so stay tuned.

\section{Handling editor Josef S Smolen \\ Contributors we both contributed equally to this editorial.}

Funding The authors have not declared a specific grant for this research from any funding agency in the public, commercial or not-for-profit sectors.

Competing interests None declared.

Patient and public involvement Patients and/or the public were not involved in the design, or conduct, or reporting, or dissemination plans of this research.

Patient consent for publication Not required.

Provenance and peer review Commissioned; internally peer reviewed.

\section{(2) OPEN ACCESS}

Open access This is an open access article distributed in accordance with the Creative Commons Attribution Non Commercial (CC BY-NC 4.0) license, which permits others to distribute, remix, adapt, build upon this work non-commercially, and license their derivative works on different terms, provided the original work is properly cited, appropriate credit is given, any changes made indicated, and the use is non-commercial. See: http:// creativecommons.org/licenses/by-nc/4.0/.

(c) Author(s) (or their employer(s)) 2021. Re-use permitted under CC BY-NC. No commercial re-use. See rights and permissions. Published by BMJ.

$$
\text { A) Check for updates }
$$

To cite Calabrese L, Winthrop KL. Ann Rheum Dis 2021;80:679-681.

Received 15 February 2021

Revised 20 February 2021

Accepted 22 February 2021

Published Online First 3 March 2021

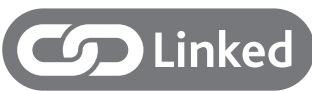

- http://dx.doi.org/10.1136/annrheumdis-2020-

219724

- http://dx.doi.org/10.1136/annrheumdis-2020219725

Ann Rheum Dis 2021:80:679-681.

doi:10.1136/annrheumdis-2021-219957

\section{ORCID iDs}

Leonard Calabrese http://orcid.org/0000-0002-17894923

Kevin L Winthrop http://orcid.org/0000-0002-3892 6947

\section{REFERENCES}

1 Alunno A, Najm A, Machado PM, et al. EULAR points to consider on pathophysiology and use of immunomodulatory therapies in COVID-19. Ann Rheum Dis 2021;80:698-706

2 Alunno A, Najm A, De Marco G. Immunomodulatory therpies for severe acute respiratory syndrome coronavirus 2 infection: a systematic reveiw to inform EULAR points to consider. Ann Rheum Dis 2021;80:803-15.

3 Polack FP, Thomas SJ, Kitchin N, et al. Safety and efficacy of the BNT162b2 mRNA Covid-19 vaccine. $N$ Engl J Med 2020;383:2603-15.

4 Baden LR, El Sahly HM, Essink B, et al. Efficacy and safety of the mRNA-1273 SARS-CoV-2 vaccine. N Engl $J$ Med 2021;384:403-16.

5 COVID-19 Real time learning network. Cdc and infectious disease Society of America, 2021. Available: https://www.idsociety.org/covid-19-real-time-learningnetwork/vaccines/vaccines/\#Phase3

6 Widge AT, Rouphael NG, Jackson LA, et al. Durability of responses after SARS-CoV-2 mRNA-1273 vaccination. N Engl J Med 2021;384:80-2.

7 Lumley SF, O'Donnell D, Stoesser NE, et al. Antibody status and incidence of SARS-CoV-2 infection in health care workers. $N$ Eng/ J Med 2021;384:533-40.

8 Day AL, Winthrop KL, Curtis JR. The effect of disease-modifying antirheumatic drugs on vaccine immunogenicity in adults. Cleve Clin J Med 2020:87:695-703.

9 Winchester N, Calabrese C, Calabrese L. The intersection of COVID19 and autoimmunity: what is our current understanding? Pathogens and Immunity 2021.

10 Woodruff MC, Ramonell RP, Lee FE-H, et al. Broadlytargeted autoreactivity is common in severe SARSCoV-2 infection. medRxiv 2020. doi:10.1101/2020.10 21.20216192. [Epub ahead of print: 23 Oct 2020].

11 Gao Z-W, Zhang H-Z, Liu C, et al. Autoantibodies in COVID-19: frequency and function. Autoimmun Rev 2021:102754:102754.

12 Zuo Y, Estes SK, Ali RA, et al. Prothrombotic autoantibodies in serum from patients hospitalized with COVID-19. Sci Trans/ Med 2020;12. doi:10.1126/ scitransImed.abd3876. [Epub ahead of print: 18 Nov 2020].

13 Woodruff MC, Ramonell RP, Nguyen DC, et al. Extrafollicular B cell responses correlate with neutralizing antibodies and morbidity in COVID-19. Nat Immunol 2020;21:1506-16.

14 Bhadelia N, Belkina A, Olson A. Distinct autoimmune antibody signatures between hospitalized acute COVID-19 patients, SARS-CoV-2 convalescent individuals, and unexposed Pre-Pandemic controls. medRxiv 2021. doi:10.1101/2021.01.21.21249176

15 Chang SE, Feng A, Meng W, et al. New-Onset IgG autoantibodies in hospitalized patients with COVID-19. medRxiv 2021. doi:10.1101/2021.01.27.2 1250559. [Epub ahead of print: 29 Jan 2021].

16 Combes AJ, Courau T, Kuhn NF, et al. Global absence and targeting of protective immune states in severe COVID-19. Nature 2021. doi:10.1038/s41586-02103234-7. [Epub ahead of print: 25 Jan 2021].

17 Moritz CP, Paul S, Stoevesandt O, et al. Autoantigenomics: holistic characterization of autoantigen repertoires for a better understanding of autoimmune diseases. Autoimmun Rev 2020;19:102450.

18 Meeting the challenge of long COVID. Nat Med 2020:26:1803.

19 del Rio C, Collins LF, Malani P. Long-Term health consequences of COVID-19. JAMA 2020:324:1723.

20 Nath A. Long-Haul COVID. Neurology 2020:95:559-60.

21 Brodin P. Immune determinants of COVID-19 disease presentation and severity. Nat Med 2021:27:28-33.

22 RECOVERY Collaborative Group, Horby P, Lim WS, et al. Dexamethasone in Hospitalized Patients with Covid-19 - Preliminary Report. N Engl J Med 2020. doi:10.1056/ NEJMoa2021436. [Epub ahead of print: 17 Jul 2020].

23 Parr JB. Time to reassess tocilizumab's role in COVID-19 pneumonia. JAMA Intern Med 2021;181:12-15.

24 Ramiro S, Mostard RLM, Magro-Checa C, et al. Historically controlled comparison of glucocorticoids with or without tocilizumab versus supportive care only in patients with COVID-19-associated cytokine storm syndrome: results of the chiC study. Ann Rheum Dis 2020;79:1143-51.

25 Horby PW, Pessoa-Amorim G, Peto L. Tocilizumab in patients admitted to hospital with COVID-19 (recovery): preliminary results of a randomised, controlled, open-label, platform trial. medRxiv 2021. 